\title{
Modulation of binding properties of amphiphilic DNA containing multiple dodecyl phosphotriester linkages to lipid bilayer membrane
}

\author{
Shingo Makishi ${ }^{\text {a }}$, Tomonori Shibata ${ }^{\text {a }}$, Masatsugu Okazaki ${ }^{a}$, Chikara Dohno ${ }^{\text {a,b, }}$ and Kazuhiko Nakatani ${ }^{\text {a,* }}$ \\ ${ }^{a}$ Department of Regulatory Bioorganic Chemistry, The Institute of Scientific and Industrial Research (ISIR), Osaka University, Ibaraki 567-0047, Japan \\ ${ }^{b}$ PRESTO, Japan Science and Technology Agency, 4-1-8 Honcho Kawaguchi, Saitama 332-0012, Japan
}

\section{ARTICLE INFO}

\section{ABSTRACT}

Article history:

Received

Revised

Accepted

Available online

\section{Keywords:}

Amphiphilic DNA

lipid membrane

liposome

SPR

\begin{abstract}
DNA is a promising functional molecule to modify and design lipid membrane functions. In order to use DNA in a hydrophilic-hydrophobic interface including lipid membrane, we have developed an amphiphilic DNA having dodecyl phosphotriester linkages (dod-DNA). Herein, we report the binding of a series of amphiphilic dod-DNAs to the lipid bilayer membrane. Surface plasmon resonance (SPR) assay and fluorescent microscopy showed that dod-DNA having three dodecyl groups at each end strongly bound to lipid membrane due to the slow dissociation rate and the dod-DNA can be used as a linear template for molecular arrangement on the membrane surface.
\end{abstract}

2009 Elsevier Ltd. All rights reserved.
Cell membrane provides hydrophilic-hydrophobic interface where a large number of proteins exert a variety of functions. Molecules that can modify the membrane properties and add novel functions are promising molecular tools for biotechnology. DNA has attracted much attention as a functional molecule due to its high specificity in hybridization and designable selfassemble property through Watson-Crick base pairing. In order to use the unique DNA properties on the membrane surface, amphiphilic (lipophilic) DNAs having hydrophobic functionalities has been developed. ${ }^{1-3}$ The amphiphilic DNAs are anchored to the surface of lipid bilayer membrane and add new properties and functions to the membrane, such as specific labeling, ${ }^{4-7}$ precise molecular arrangement, ${ }^{8,9}$ vesicle aggregation $^{10-12}$ and fusion. ${ }^{13-15}$ Recent progress on DNA nanotechnology combined with the amphiphilic DNAs has expanded the potential of DNA-based designer functions on the lipid bilayer membrane, ${ }^{16-24}$ including light harvesting devices ${ }^{23,24}$ and synthetic ion channels. ${ }^{21,22}$ Control of DNA binding properties to the lipid membrane, including binding affinity and orientation with respect to the membrane surface, is important to make the best possible use of a variety of functional DNA structures on the lipid membrane.

We have recently developed amphiphilic DNAs containing hydrophobic dodecyl phosphotriester linkages instead of natural

\footnotetext{
* Corresponding author. Tel.: +81-6-6879-8455; fax: +81-6-68798459; e-mail: cdohno@sanken.osaka-u.ac.jp, nakatani@sanken.osaka-u.ac.jp
}

hydrophilic phosphate backbone (dod-DNA, Figure 1a). ${ }^{25,26}$ The dodecyl-modified hydrophobic backbone has no electric charge and the dodecyl groups positioned at the outermost surface of the DNA helix. Similar to amphipathic $\alpha$-helix peptides having hydrophobic faces, dod-DNA having appropriate hydrophobic regions could be a suitable binder to lipid membrane surface. We herein report the binding of a series of amphiphilic dod-DNAs to the lipid membrane surface. The binding properties were investigated by surface plasmon resonance (SPR) assay and were optimized for the use of dod-DNA on the lipid membrane.
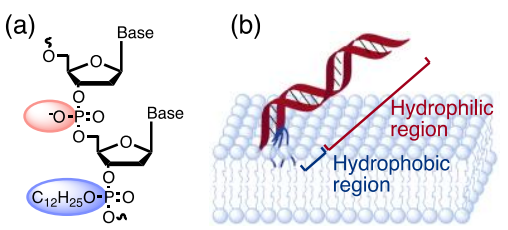

(c)

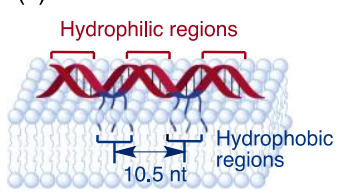

Figure 1. (a) Chemical structure of amphiphilic DNA (dod-DNA) used in this study. Schematic illustration of lipid membrane anchored dod-DNAs with (b) a single hydrophobic region at the terminal and (c) two hydrophobic regions in the same face of the DNA helix by introducing at intervals of 1 turn (10.5 nucleotides, nt) of the helix.

While introduction of hydrophobic functionalities at the end of one DNA strand has been widely used to prepare membraneanchored DNAs (Figure 1b), ${ }^{1-3}$ we anticipated that binding affinity and orientation of amphiphilic DNAs to the lipid membrane could be tuned by the number and location of the hydrophobic modifications in the DNA sequence (Figure 1). Single hydrophobic region at the terminal of DNA would anchor the DNA to membrane surface (Figure 1b). Multiple hydrophobic 

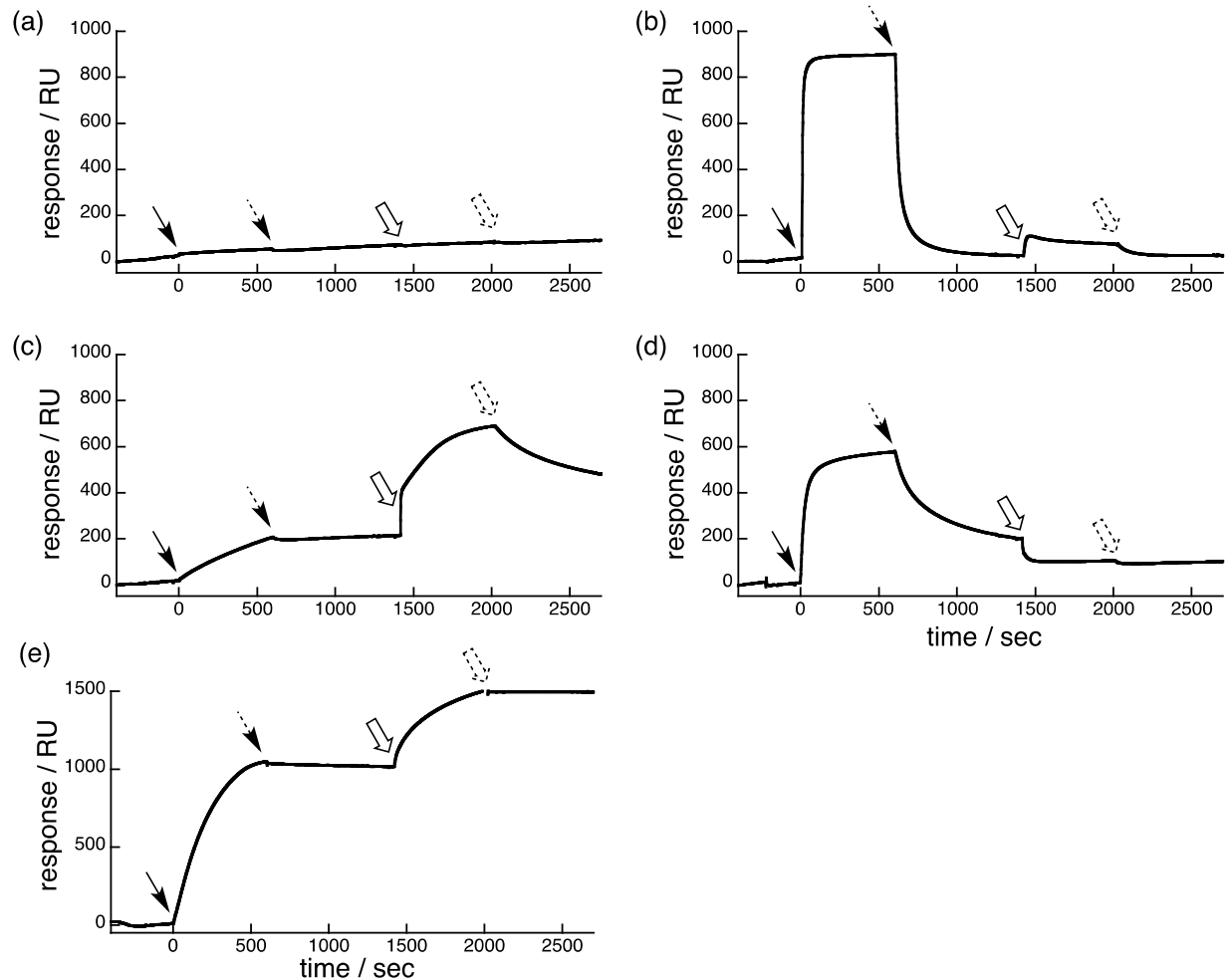

Figure 2. Sensorgrams of dod-DNA bindings to the lipid bilayer and their hybridizations. POPC liposomes are deposited on L1 sensor chip, followed by injections of dod-DNAs $(\mathrm{t}=0$, black solid arrows) and their complementary DNAs $(\mathrm{t}=1400$, white arrows). (a) dod-DNA1. (b) dod-DNA2. (c) dod-DNA3. (d) dod-DNA4, (e) dod-DNA5. Dashed arrows indicate the beginning of running buffer injection (washing steps, $\mathrm{t}=600$ and 2000).

Table 1. Sequences of DNAs used in this study. ${ }^{\text {a }}$

\begin{tabular}{|c|c|}
\hline dod-DNA1 & 5'-TR TTTTCACCGACCACGC-3' \\
\hline dod-DNA2 & $5^{\prime}-\mathrm{T}_{\mathrm{R}} \mathrm{T}_{\mathrm{R}}$ TTTCACCGACCACGC-3' \\
\hline dod-DNA3 & $5^{\prime}-T_{R} T_{R} T_{R}$ TTCACCGACCACGC-3' \\
\hline dod-DNA4 & 5'-TAGCTACTT $\mathrm{R}_{\mathrm{R}} \mathrm{T}_{\mathrm{R}} \mathrm{T}_{\mathrm{R}}$ TCATCGT-3' \\
\hline dod-DNA5 & 5'- $\mathrm{C}_{\mathrm{R}} \mathrm{T}_{\mathrm{R}} \mathrm{C}_{\mathrm{R}}$ CAGTTCGTGAGTGATGTATAGCGATGTCG ${ }_{\mathrm{R}} \mathrm{T}_{\mathrm{R}} \mathrm{C}_{\mathrm{R}} \mathrm{T-3} \mathbf{3}^{\prime}$ \\
\hline DNA6 & 5'-GCGTGGTCGGTGAAAAA-3' \\
\hline DNA7 & 5'-CTCCAGTTCGTGAGTGATGTATAGCGATGTCGTCT-3' \\
\hline DNA8 & 5'-AGACGACATCGCTATACATCACTCACGAACTGGAG-3' \\
\hline Су3-DNA9 & 5'-Суз-АTСАСTCACGAACTGGAG-3' \\
\hline Cy5-DNA10 & 5'-AGACGACATCGCTATAC-Cy5-3' \\
\hline
\end{tabular}

"Hydrophobic triester linkage is indicated by a subscript " $R$ ".

regions at intervals of 1 turn (10.5 nucleotides) of B-DNA helix would strictly define orientation of the membrane-bound DNA with respect to the membrane plane, where the DNA lies down on the membrane surface (Figure 1c). We first evaluated a binding of amphiphilic dod-DNAs having hydrophobic dodecyl phosphotriester linkages at the terminal, which can act as an anchor on the membrane surface.

We have synthesized a series of dod-DNAs having one to three dodecyl groups at the 5'-end (dod-DNA 1-3, Table 1) according to previously established synthetic procedure. ${ }^{25}$ Bindings of the dod-DNAs to lipid membrane were evaluated by surface plasmon resonance (SPR) technique with a L1 sensor chip (Biacore) immobilized with 1-palmitoyl-2-oleoyl-snglycero-3-phosphatidylcholine (POPC) liposome. ${ }^{27,28}$ For each SPR experiment, DNA hybridization with the surface-bound dodDNA was monitored by a subsequent injection of the complementary DNA. dod-DNA1 having a single dodecyl group showed no apparent increase in SPR response, indicating a very weak interaction to the lipid membrane under the condition (Figure 2a, injection of the dod-DNA was depicted by solid arrow). In contrast, apparent rises in SPR response were observed upon injection of dod-DNA2 and dod-DNA3. The curve shapes indicate the different kinetics of the dod-DNAs binding to the lipid membrane; dod-DNA2 having two dodecyl groups showed rapid association and dissociation (Figure 2b), while dod-DNA3 having three dodecyl groups showed slow association and dissociation resulting in retention of the dod-DNA3 on the membrane (Figure 2c). With increasing number of dodecyl groups, the binding affinity to the lipid membrane increased because of the slow dissociation rate. Although the $K_{d}$ value of dod-DNA3 with the lipid membrane could not be precisely determined because of the slow dissociation, dod-DNA3 (dissociation rate, $k_{\mathrm{d}}<6 \times 10^{-5} \mathrm{~s}^{-1}$ ) bound to the lipid membrane at least 20 times more tightly than dod-DNA2 $\left(k_{\mathrm{d}}=4 \times 10^{-2} \mathrm{~s}^{-1}\right.$, $\left.\mathrm{K}_{\mathrm{d}} \approx 1 \times 10^{-6} \mathrm{M}\right)$. Although dod-DNA4 has the same number of dodecyl groups as that of dod-DNA3 at the middle of the sequence, its dissociation was much faster than dod-DNA3 (Figure $2 \mathrm{~d}, k_{\mathrm{d}}=1 \times 10^{-3} \mathrm{~s}^{-1}$ ). Terminal modification with multiple dodecyl groups is effective to immobilize DNA tightly on lipid bilayer membrane. Subsequent injection of the complementary DNA (DNA6) gave another rise in the sensorgram for dod-DNA3 (Figure 2c, white arrow at $t=1400$ $\mathrm{sec})$. The membrane-anchored dod-DNA3 could undergo hybridization with the complementary DNA on the lipid membrane.

Having established that a consecutive three dodecyl phosphotriester linkages functions as a hydrophobic anchor for immobilizing DNA onto the lipid membrane, we next examined binding of dod-DNA having two separate hydrophobic regions (dod-DNA5), which presumably restricts the binding orientation of the DNAs on the membrane and enhances the binding affinity (Figure 1c). In order to facilitate the binding on the flat lipid membrane, two hydrophobic modification sites in dod-DNA5 are separated by three turn of the helix. Since the hydrophobic modification at the terminal is more favorable for the binding to 
the lipid membrane (Figure 2c, d), the hydrophobic regions in dod-DNA5 are introduced at both ends of the strand.

dod-DNA5 showed a similar binding sensorgram to that of dod-DNA3 having three dodecyl groups at the one $5^{\prime}$-end, but with increased association rate (Figure 2e, black solid arrow at $\mathrm{t}$ $=0 \mathrm{sec}$ ). Subsequent injection of the complementary DNA (DNA8) gave another rise in the sensorgram for dod-DNA5 (Figure 2e, white arrow at $\mathrm{t}=1400 \mathrm{sec}$ ). Both after the dodDNA5 binding and after the DNA hybridization, no dissociation from the surface was observed under the condition, indicating that dod-DNA5 bind very tightly to the membrane surface and retain hybridization properties on the surface. We measured melting temperatures $\left(T_{\mathrm{m}}\right)$ of dod-DNA3/DNA6, dodDNA5/DNA8 and unmodified DNA7/DNA8 duplexes with and without POPC liposome by fluorescence changes of SYBR Green during a linear temperature transition from $10{ }^{\circ} \mathrm{C}$ to $95{ }^{\circ} \mathrm{C}$ at $0.3{ }^{\circ} \mathrm{C} / \mathrm{min}$ (Table 2). The $T_{\mathrm{m}}$ of dod-DNA5 duplex was increased by the presence of POPC liposome $\left(\Delta T_{\mathrm{m}}=5.0^{\circ} \mathrm{C}\right)$, while the others were not. These data suggested that dod-DNA5 bound to the lipid membrane with both two hydrophobic regions and the binding suppressed the dehybridization of the DNA duplex.

Table 2. Melting temperatures of DNA duplexes $(2 \mu \mathrm{M})$ with and without POPC liposome. ${ }^{\text {a }}$

\begin{tabular}{lccc}
\hline & $\begin{array}{c}T_{\mathrm{m}}\left[{ }^{\circ} \mathrm{C}\right] \\
\text { without liposome }\end{array}$ & $\begin{array}{c}T_{\mathrm{m}}\left[{ }^{\circ} \mathrm{C}\right] \\
\text { with liposome }\end{array}$ & $\Delta T_{\mathrm{m}}\left[{ }^{\circ} \mathrm{C}\right]$ \\
\hline $\begin{array}{c}\text { dod-DNA3 } \\
\text { /DNA6 } \\
\text { dod-DNA5 } \\
\text { /DNA8 }\end{array}$ & 67.4 & 66.2 & -1.2 \\
$\begin{array}{l}\text { DNA7 } \\
\text { /DNA8 }\end{array}$ & 68.5 & 73.5 & 5.0 \\
& 77.9 & 78.4 & 0.5 \\
$\begin{array}{l}{ }^{\mathrm{a}} \Delta T_{\mathrm{m}} \text { values were calculated from the equation: } \Delta T_{\mathrm{m}}=T_{\mathrm{m} \text { (with liposome) }}-T_{\mathrm{m}} \\
\text { (without liposome). }\end{array}$
\end{tabular}

To show that dod-DNA can be used as a one dimensional, linear template on lipid membrane surfaces, we designed liposome labeling experiments using fluorescence-labeled DNAs. Two fluorescent-labeled DNAs (Cy3-DNA9 and Cy5-DNA10, Table 1) were designed to adjacently hybridize with the membrane bound template DNA, dod-DNA5 (Figure 3a). If all components are correctly assembled on the liposome surface, Förster resonance energy transfer (FRET) between Cy3 and Cy5 occur on the surface. Excitation of $\mathrm{Cy} 3$ fluorophore in the presence of all components (i.e., two fluorescent labeled DNAs, dod-DNA5, and POPC liposome) produced an emission at 670 $\mathrm{nm}$ with concomitant decrease of the original emission at 570 $\mathrm{nm}$, showing the occurrence of FRET from $\mathrm{Cy} 3$ to $\mathrm{Cy} 5$ (Figure 3b). SPR data (Figure 2e) and another FRET experiment using a fluorescently labeled liposome (POPC/NBD-DPPE $=100 / 1$ ) (Figure S2) indicate that the observed FRET occurred on the liposome surface with the aid of dod-DNA5. Fluorescence images of the liposome labeled with the DNA FRET pairs were obtained by fluorescence microscopy equipped with a FRET filter set, which consists of the donor excitation filter $(525 / 45 \mathrm{~nm}$ bandpass) and the acceptor emission filter (695/55 nm bandpass). Only in the presence of the complete set of DNAs, liposome exhibited the acceptor Cy5 fluorescence (Figure 3c). When any of the single DNA components was omitted or unmodified DNA (DNA7) was used instead of dod-DNA5, no apparent acceptor fluorescence was observed on the liposomes (Figure 3c, right image, Figure S3). These data clearly showed that dod-DNA5 functioned as a template for molecular arrangement on the lipid membrane surface. (a)

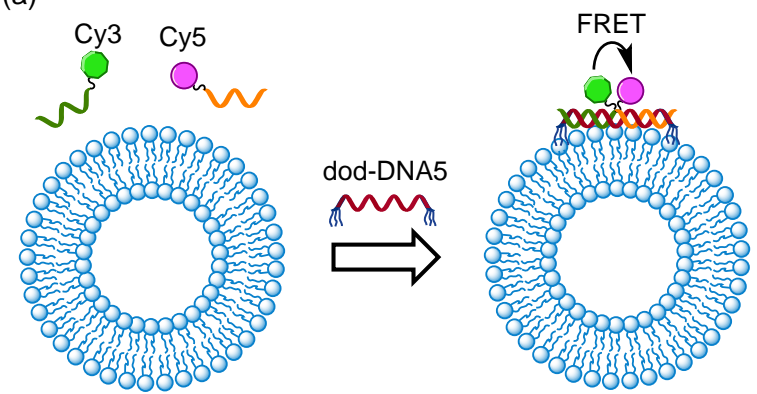

(b)

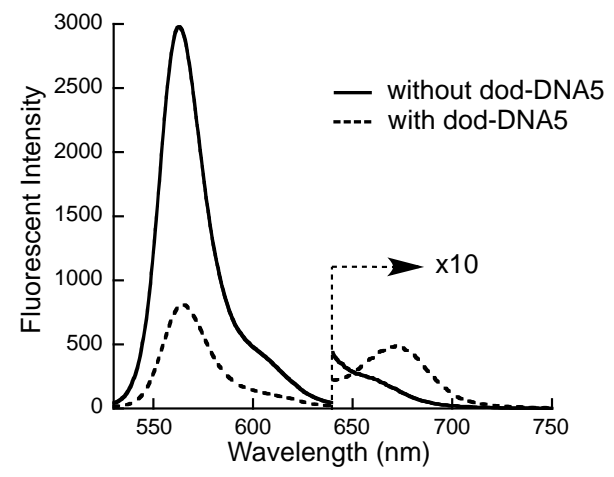

(c)
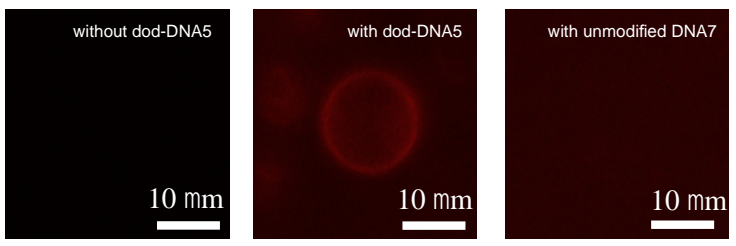

without dod-DNA5

with dod-DNA5

with unmodified DNA7
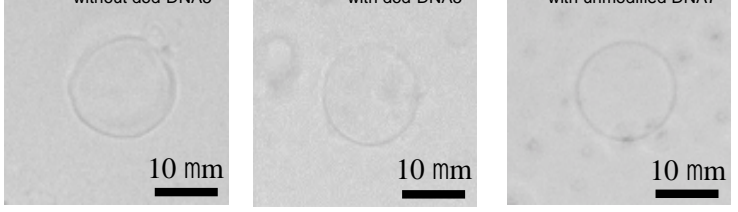

Figure 3. (a) Schematic illustration of a liposome labeling experiments using dod-DNA5 and DNAs labeled with a FRET pair. (b) Fluorescent spectra of mixtures containing Cy3-DNA9, Cy5-DNA10 and POPC liposome in the presence and absence of dod-DNA5. (c, top) Fluorescent microscopic images and (c, bottom) bright field images. All fluorescent images were taken with the same exposure time. (left) Without dod-DNA5; (middle) with dod-DNA5; (right) unmodified DNA7 instead of dod-DNA5.

In summary, we have reported the binding of dod-DNAs to lipid bilayer membrane, whose binding affinity and orientation could be tuned by number and locations of hydrophobic modification sites. dod-DNA having three dodecyl groups at each end showed strong binding to POPC membrane due to the slow dissociation rate, which can be used as a linear template for molecular arrangement on the surface of lipid bilayer membranes. Amphiphilic dod-DNAs with appropriate hydrophobic modifications are useful scaffold on the lipid membrane for construction of finely designed DNA nanostructures that can add a variety of functions to the lipid membrane.

\section{Acknowledgments}

The authors thank Prof. J. Kikuchi and Dr. K. Yasuhara of Nara Institute of Science and Technology for the liposome preparations. This work was supported by PREST-JST 
(Precursory Research for Embryonic Science and Technology, Japan Science and Technology Agency).

\section{References and notes}

1. Kwak, M.; Herrmann, A. Chem. Soc. Rev. 2011, 40, 5745.

2. Patwa, A.; Gissot, A.; Bestel, P.; Barthelemy, P. Chem. Soc. Rev. 2011, 40, 5844 .

3. Edwardson, T. G.; Carneiro, K. M.; McLaughlin, C. K.; Serpell, C J.; Sleiman, H. F. Nat. Chem. 2013, 5, 868.

4. Kurz, A.; Bunge, A.; Windeck, A.-K. ; Rost, M.; Flasche, W.; Arbuzova, A.; Strohbach, D.; Müller, S.; Liebscher, J.; Huster, D.; Herrmann, A. Angew. Chem. Int. Ed. 2006, 45, 4440.

5. Schade, M.; Knoll, A.; Vogel, A.; Seitz, O.; Liebscher, J.; Huster, D.; Herrmann, A.; Arbuzova, A. J. Am. Chem. Soc. 2012, 134 20490.

6. Borisenko, G. G.; Zaitseva, M. A.; Chuvilin, A. N.; Pozmogova, G E. Nucleic Acids Res. 2009, 37.e 28.

7. Tokunaga, T.; Namiki, S.; Yamada, K.; Imaishi, T.; Nonaka, H.; Hirose, K.; Sando, S. J. Am. Chem. Soc. 2012, 134, 9561.

8. Yoshina-Ishii, C.; Miller, G. P.; Kraft, M. L.; Kool, E. T.; Boxer, S. G. J. Am. Chem. Soc. 2005, 127, 1356

9. Borjesson, K.; Tumpane, J.; Ljungdahl, T.; Wilhelmsson, L. M.; Nordén, B.; Brown, T.; Martensson, J.; Albinsson, B. J. Am. Chem. Soc. 2009, 131, 2831

10. Jakobsen, U.; Simonsen, A. C.; Vogel, S. J. Am. Chem. Soc. 2008 , 130, 10462

11. Teramura, Y.; Chen, H.; Kawamoto, T.; Iwata, H. Biomaterials 2010, 31, 2229.

12. Selden, N. S.; Todhunter, M. E.; Jee, N. Y.; Liu, J. S.; Broaders, K. E.; Gartner, Z. J. J. Am. Chem. Soc. 2012, 134, 765.

13. Stengel, G.; Zahn, R.; Höök, F. J. Am. Chem. Soc. 2007, 129, 9584.

14. Chan, Y. H. M.; van Lengerich, B.; Boxer, S. G. Proc. Natl. Acad. Sci. U. S. A. 2009, 106, 979
15. Lygina, A. S.; Meyenberg, K.; Jahn, R.; Diederichsen, U. Angew. Chem. Int. Ed. 2011, 50, 8597.

16. Baldelli Bombelli, F.; Betti, F.; Gambinossi, F.; Caminati, G.; Brown, T.; Baglioni, P.; Berti, D. Soft Matter 2009, 5, 1639.

17. Laisne, A.; Ewald, M.; Ando, T.; Lesniewska, E.; Pompon, D. Bioconjugate Chem. 2011, 22, 1824.

18. Börjesson, K.; Lundberg, E. P.; Woller, J. G.; Nordén, B.; Albinsson, B. Angew. Chem. Int. Ed. 2011, 50, 8312.

19. Lundberg, E. P.; Feng, B.; Saeid Mohammadi, A.; Wilhelmsson, L. M.; Nordén, B. Langmuir 2013, 29, 285.

20. Suzuki, Y.; Endo, M.; Yang, Y.; Sugiyama, H. J. Am. Chem. Soc. 2014, 136, 1714.

21. Langecker, M.; Arnaut, V.; T. G. Martin, J. List, S. Renner, M. Mayer, H. Dietz, F. C. Simmel, Science, 2012, 338, 932.

22. Burns, J. R.; Stulz, E.; Howorka, S. Nano Lett 2013, 13, 2351

23. Borjesson, K.; Wiberg, J.; El-Sagheer, A. H.; Ljungdahl, T.; Martensson, J.; Brown, T.; Nordén, B.; Albinsson, B. ACS Nano 2010, 4, 5037

24. Woller, J. G.; Hannestad, J. K.; Albinsson, B. J. Am. Chem. Soc. 2013, 135, 2759

25. Dohno, C.; Shibata, T.; Okazaki, M.; Makishi, S.; Nakatani, K. Eur. J. Org. Chem. 2012, 5317.

26. Shibata, T.; Dohno, C.; Nakatani, K. Chem. Commun. 2013, 49, 5501.

27. Cooper, M. A.; Hansson, A.; Löfås, S.; Williams, D. H. Anal. Biochem. 2000, 277, 196.

28. Mozsolits, H.; Aguilar, M. I. Biopolymers 2002, 66, 3.

\section{Supplementary Material}

Supplementary data associated with this article can be found in the online version. 


\section{Graphical Abstract}

To create your abstract, type over the instructions in the template box below.

Fonts or abstract dimensions should not be changed or altered.

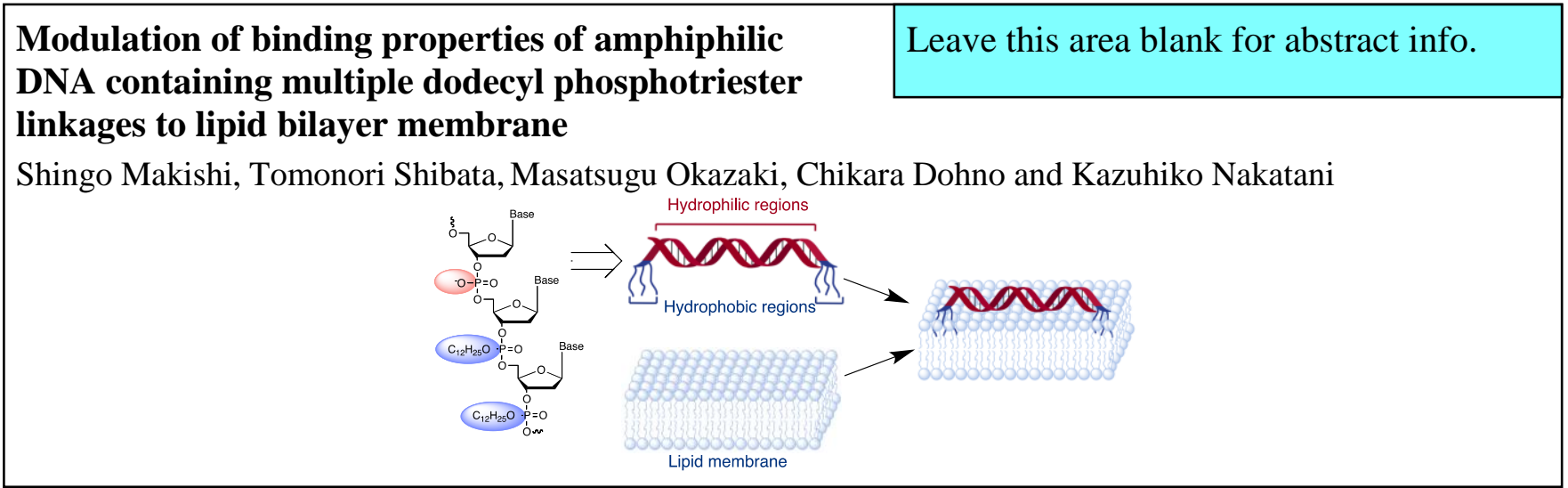

